\title{
El hiṣn de Almansa (Albacete): fortificaciones y poblamiento
}

The hiṣn Almansa: fortifications and settlements

\author{
Pedro Jiménez Castillo a ${ }^{\text {, José Luis Simón García }}{ }^{\text {b }}$ \\ ${ }^{a}$ Escuela de Estudios Árabes - Consejo Superior de Investigaciones Científicas, Granada, Spain, pedro@eea.csic.es \\ ${ }^{\mathrm{b}}$ Universidad de Alicante, Alicante, Spain, simon_josgar@gva.es
}

\begin{abstract}
Because of its spectacular location and its good state of conservation, the image of the castle of Almansa has been widely reproduced in publications of informative and even tourist purpose. The building is the result of construction, remodeling, plundering, demolition, blasting and restoration processes, carried out over more than eight centuries, although the current aspect is essentially that of the castle remodeled by Don Juan Pacheco, Marquis of Villena, in the fifteenth century, that camouflage or suppress those made previously, whether taifa, almohad or feudal. In this paper we are interested in the castle (hiṣn) of Almansa in Islamic times, but not strictly from the architectural point of view but its history as a central element that organized an administrative district or iqlim. In this sense, Almansa offers very relevant research possibilities, because we know exactly the delimitation of its district in almohad times thanks to the Castilian documentation after the conquest, we have some data from the Arabic texts and, above all, we have of a very detailed archaeological information from intensive field surveys. Therefore, we will study the different types of castral buildings, fortresses and towers, as well as settlements -farmhouses, hamlets and shelters- in order to get information about the evolution of the modes of occupation and exploitation of the territory between the eleventh and thirteenth centuries, which will be modified throughout the feudal period, becoming a rare case in the scientific literature to date.
\end{abstract}

Keywords: Al-Andalus, castles, farmsteads, rural settlement.

\section{Introducción}

Hasta hace pocos años, apenas existía bibliografía acerca de la historia del Corredor de Almansa y las tierras de Montearagón en época islámica, tal y como ya expusimos detalladamente en otros trabajos (Simón, 2011a, p. 169). No obstante, a partir de fechas recientes se ha comenzado a paliar esta escasez gracias, fundamentalmente, a los resultados de la actividad arqueológica. Centrándonos en nuestra propia aportación, en 1999 elaboramos un trabajo inicial sobre el castillo de Almansa que, pese a ser una de las fortificaciones españolas más representadas en los numerosos manuales y recopilaciones de este tipo de edificios, carecía hasta ese momento de un análisis riguroso de los aspectos arqueológicos, arquitectónicos o históricos. Continuamos esa línea de investigación con el estudio de las estructuras defensivas dispersas por el Corredor de Almansa (Simón, 2000, 2002); desarrollando también trabajos relacionados con la arqueología medieval de la zona, como las codirecciones de las intervenciones arqueológicas asociadas a los proyectos de restauración de los castillos de Almansa, Caudete, la Torre de Bogarra, Montealegre del Castillo, la Puerta de Diablos y Tiradores de Chinchilla, el castillo de Socovos o la Torre de Gorgojí (Simón, 2007, p. 253), así como las prospecciones 


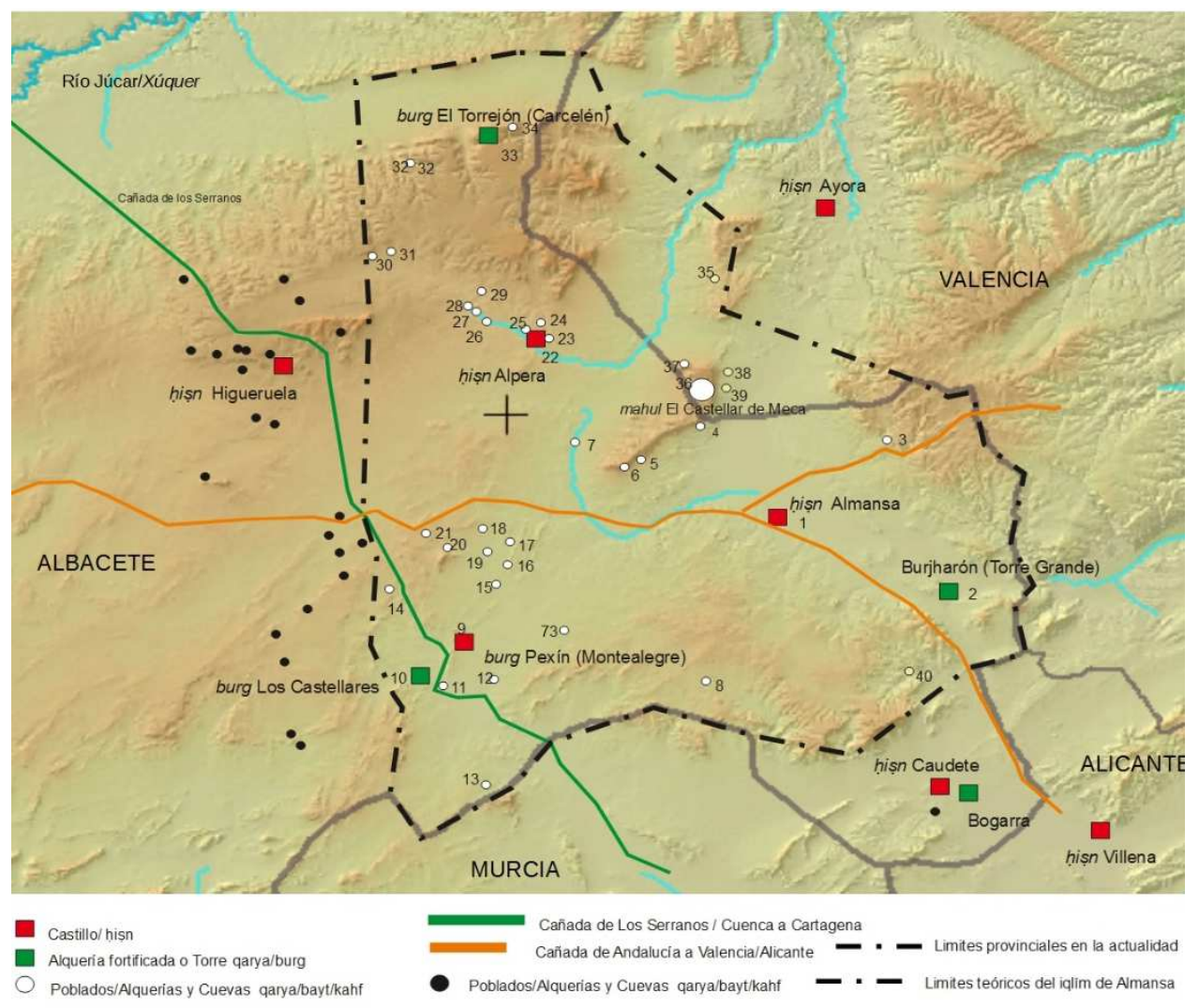

Fig. 1. 1) Castillo de Almansa; 2) Torre de Burharón (Almansa); 3) Hoya Matea (Almansa); 4) Cueva Negra (Almansa); 5) Abrigos del Mugrón I y II (Almansa); 6.) Cueva del Puntal del Mugrón (Almansa); 7) El Carrascal (Bonete); 8) Jódar (Almansa); 9) Castillo de Montealegre del Castillo; 10) Los Castellares (Montealegre del Castillo); 11) Cerrico don Felipe (Montealegre del Castillo); 12) Casa de los Calderones (Montealegre del Castillo); 13) Morra de Charrante (Montealegre del Castillo); 14) Fuentechilla (Chinchilla); 15) Casa de doña Juliana (Montealegre del Castillo); 16) Casas Viejas (Almansa); 17) Fuensanta (Almansa); 18) Lomas de Cuevas Negras (Bonete); 19) Bancal de las Tinajas (Bonete); 20) El Chisnar (Bonete); 21) Fuente Somera (Bonete); 22) Castillo de San Gregorio (Alpera); 23) Bancal del Reviejo (Alpera); 24) Loma de la Vega (Alpera); 25) Cueva Negra de la Vega, (Alpera); 26) Tobillos (Alpera); 27) Casa del Sol II (Alpera); 28) Casa del Sol, (Alpera); 29) Las Fuentes (Alpera); 30) Casa de la Zorra (Alpera); 31) Malefatón (Alpera); 32) Cerro Fino (Alatoz); 33) Los Torrejones de Carcelén; 34) Cerro Dolonche (Carcelén); 35) Las Torcas (Ayora); 36) El Castellar de Meca (Ayora); 37) Abrigo y Arco de San Pascual (Ayora); 38) Hoya Marín (Ayora); 39) Pozo de Egea (Ayora); 40) Olula II (Almansa).

en todo el ámbito de la provincia de Albacete, incluido el Corredor de Almansa, con motivo de la redacción de las cartas arqueológicas de los diferentes municipios. A partir de la información aportada por estos estudios y los de otros investigadores durante las dos últimas décadas, en el presente trabajo trataremos de llevar a cabo una síntesis e interpretación general, y no tanto proporcionar datos novedosos.

El área objeto de estudio es el distrito castral del iqlìm de Almansa (Fig. 1), situado en el espacio geográfico conocido en la actualidad como el Corredor de Almansa, en el sector oriental de la actual provincia de Albacete, al que se le unió a finales del siglo XIX el término de Caudete, adscrito física e hidrológicamente a la comarca alicantina del Alto Vinalopó e históricamente al Reino de Aragón; así como una parte de las tierras de Chinchilla de Montearagón, hoy en día denominadas administrativamente como MonteIbérico. En el análisis del territorio hemos incluido una serie de yacimientos, como de El 
Castellar de Meca y la aldea de San Benito, ambos actualmente en el término de Ayora (Valencia) pero adscritos cultural y geográficamente al hiṣn de Almansa, sin los cuales la visión de conjunto sería sesgada e incompleta.

Como casi todas las sociedades preindustriales, la economía andalusí estaba basada principalmente en las actividades agropecuarias, donde factores geográficos como los suelos, el clima, la hidrología o la vegetación y la fauna son determinantes; por consiguiente, es necesario tomar en consideración la geografía del territorio en cuestión para esta aproximación histórica. El Corredor de Almansa se sitúa en una zona inscrita en la región suroriental de la Meseta Ibérica, donde confluyen los dominios geológicos del Prebético y la Cordillera Ibérica (Ponce, 1989). Presenta un clima de transición entre las tierras valencianas y las planicies manchegas en cuanto a temperaturas y pluviometría, debido esencialmente a la altitud del territorio -por encima de los $700 \mathrm{~m}$ en su mayor parte- y a las barreras de los macizos montañosos alicantinos que frenan los efectos marítimos. Todas estas circunstancias han modelado un paisaje donde la escasez hídrica ha condicionado la elección de los lugares de asentamiento y los posibles aprovechamientos del medio; y donde la agricultura de secano, con la triada mediterránea como base -cereal, olivo y vid- y esencialmente los pastos, han supuesto de forma secular el sustento de los grupos humanos desde la Prehistoria (Simón, Simón, 2018, p. 101).

\subsection{Fuentes árabes y toponimia}

En la descripción del sureste de la península que redactó al-'Uḍī en el siglo XI señalaba como ciudades (mudun, sing. madinna) de la cora de Tudmīr, y concretamente de la actual provincia de Albacete, Chinchilla, Iyu(h) al-Sahl (El Tolmo de Minateda) (Carmona, 2009) y Taybaliyya (Taibilla). En los itinerarios del mencionado geógrafo árabe aparecen otras poblaciones menores como Tubarra (Tobarra) o San Bitru (Las Peñas de San Pedro) (Lorrio, Simón y Sánchez, 2014, p. 73); pero nada se dice de Almansa, debido seguramente a la escasa entidad del asentamiento en este momento. Tampoco se identifica el Castellar de Meca (Ayora-Valencia), a pesar de la considerable extensión del despoblado, bien por su adscripción a la Cora de Valencia, tal y como señala Gutiérrez (1996, p. 30), o por estar ya en estos momentos en avanzada decadencia.

La primera referencia al lugar de Almansa se encuentra en la obra de geografía y viajes de alIdrīsī, quien registra que "de Játiva a Almansa hay veinticinco millas; entre Almansa y Ayora existen fuentes y ríos, por el Occidente, hay doce millas" (Abid Mizal, 1989, pp. 94, 304), es decir, que hacia la primera mitad del siglo XII ya existía en Almansa un núcleo poblacional lo suficientemente importante como para que el geógrafo indicara su ubicación y la distancia a que se encontraba de Játiva, el principal núcleo urbano de la zona. Y no solo eso, pues, además, se detalla la distancia respecto a la localidad de Ayora y una característica física de la zona en dicho recorrido, la existencia de fuentes y ríos.

Aunque no son abundantes los topónimos de origen árabe en el sureste de la provincia de Albacete en general, debido a la fuerte despoblación de la zona en época bajomedieval, perviven alguno que frecuentemente aportan información histórica de interés, como los de Alpera; Qabdhaq (Caudete) que a su vez deriva del latino Caput Aquae, así como los topónimos con el prefijo burj (torre), como La Torre Grande en Almansa o Burjaharón -(torre) de Hārūn-, que en ocasiones se ha confundido con la Bogarra de Caudete y con la Bogarra albaceteña. A falta de un estudio toponímico en profundidad, sobre todo de aquellos que hacen referencia a determinados lugares como El Mugrón, la Alcudia en Caudete, Los Algezares de Montealegre del Castillo, Alhama de Chinchilla, etc., hay que añadir los de Bonete o Gonet y Pechín. Otros, como Giravalencia, muestran el empleo del término yabal más una desinencia, en este caso Valencia, circunstancia que tendrá un perfecto significado arqueológico e histórico. En su análisis de las rutas viales de la Mancha Oriental, Franco (1995) destaca la presencia de topónimos derivados del árabe relacionados con la medición de distancias como al-manșaf "la mi- 
tad del camino", por encontrarse a mitad del trayecto entre dos ciudades más importantes (Pocklington, 2010, p. 155); rubça, un cuarto (del camino) en árabe, que derivó en la fonética castellana de Rubio, del cual podría venir Corral Rubio. El manzil, posada o venta en el camino o cerca del mismo, también pudo dar lugar a algunos topónimos.

El análisis de la toponimia y microtoponimia de cada término municipal permite recoger una reducida nómina de topónimos presumiblemente de época andalusí. Incluso extendiendo nuestra pesquisa algo más allá del núcleo central de nuestra área de estudio, podemos comprobar que casi ninguno es de origen gentilicio y la mayoría parecen simplemente descriptivos, como Algibarrón (Chinchilla); Ardalejo, El Morabio y Oroví, (Higueruela); Los Alterones, Caserío Alhama y el Amarejo (Hoya-Gonzalo); Aguaza (Corral-Rubio); Las Anorias (Pétrola); Los Algezares (Montealegre del Castillo) y Albalat (Caudete). El topónimo Rubaldea (Albacete), documentado desde la Edad Media, debe remontar al árabe $R u b$ ' al-Day'a, literalmente "cuarto de la aldea", donde la voz rub " cuarta parte, cuarto" se referirá seguramente a una parcela de tierra, o dehesa, que determinada aldea tenía derecho a explotar (Pocklington, 2010, pp. 152-153). En el término de Almansa aparece el topónimo Sujel, denominación de una rambla, caserío, laguna y fuente derivado del diminutivo árabe estándar Suhayl "pequeño llano" (Pocklington, 2010, p. 159). Alcadozo procede del

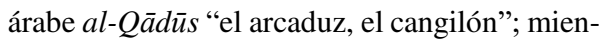
tras que Aljubé (Tobarra) parece remontar a alŶubayn "los dos aljibes", a partir de la raíz $\hat{y} u b b$ "aljibe" (Pocklington, 2010, p. 153). El topónimo Albacete procede del término al-Basīt "el llano", documentado en las fuentes árabes desde el s. XII (Pocklington, 2010, p. 158). El pago de Las Albaidas (Albacete), situado al sur del Acequión, procede del hispano-árabe alBayḍa "la blanca", con el probable significado de "tierras de secano"; frente a éste se sitúa la zona de Albaidel, diminutivo del nombre anterior formado con el sufijo mozárabe -el (Pocklington, 2010, p. 159). Albatana, en Higueruela, se remontaría al árabe al-Bitānna "el badén" (Pocklington, 2010, p. 160).
Los escasos ejemplos de carácter gentilicios parecen vinculados al nombre de algún personaje en concreto, como Verlupe o Venlupe (Chinchi1la), relativo al linaje Ibn Lubb, a su vez derivado del nombre propio andalusí Lubb "Lope, Lobo" (Pocklington, 2010, p. 149). El paraje de El Arabí (Montealegre del Castillo), que se extiende al norte del Monte Arabí, y el cercano cerro de El Arabinejo, derivan sus nombres del gentilicio "Arabī "árabe", nombre de familia o apodo que llevara originalmente algún personaje importante o propietario de la zona (Pocklington, 2010, p. 150). Más alejado se encuentra el pago de Abenuj o Abenuz (Tobarra) parecen haber tomado su nombre de Ibn Hūd, el caudillo árabe que se alzó contra los almohades en 1238; la misma etimología que El Menjú, en Cieza. Finalmente, el topónimo de las Casas de Melegriz o Melegrís, en el término municipal de Albacete, procede del nasab árabe ibn Idrīs "Hijo de Idrīs" (Pocklington, 2010, p. 149).

Unos pocos resultan algo más informativos, pues aluden a las características o naturaleza del asentamiento, como Bete (Higueruela) del árabe bayt "casa"; o Zucaña (Almansa), que remontaría al diminutivo sukayna del vocablo sakan "vivienda, morada". Quizás estos topónimos puedan asociarse con algunos asentamientos andalusíes de tamaño mínimo, consistentes en una o dos casas aisladas, que eran relativamente abundantes a juzgar por la información proporcionada por las prospecciones. El nombre del pago de Alcoraya, ubicado 2,5 km al noreste de Caudete, procede claramente del árabe al-Qurayya "la pequeña alquería", diminutivo de qarya "alquería, caserío", y podría estar en relación con los establecimientos que hemos descrito en los apartados anteriores; de hecho, el paraje en cuestión es análogo al de las alquerías en llano que venimos examinando (Pocklington, 2010, p. 149). Resumiendo, el análisis de la escasa toponimia medieval que se ha conservado muestra la inexistencia de nombre de origen tribal árabe o bereber; la mayoría designan elementos del paisaje, accidentes geográficos, nombres individuales o se refieren a la categoría del asentamiento definiéndolo como caserío o pequeña alquería. 


\section{El territorio castral}

La cabeza administrativa del extenso territorio que comprendía el Corredor de Almansa era la ciudad de Chinchilla (madīnat Šantiŷŷāla o Ŷinŷāla) ${ }^{1}$, considerada como la Saltigi romana, que se hallaba en el límite noroccidental de la cora de Tudmīr, según al-'Ud́rī (1965, pp. 42, 63). Ubicada sobre un espolón rocoso en el extremo suroccidental del conjunto montañoso de Montearagón, en el centro de la actual provincia de Albacete, entre el valle del Júcar y las tierras del Corredor de Almansa que permiten el paso desde el Vinalopó y La Costera o las tierras altas de Murcia hacia el centro de la Meseta (Ponce, 1989). Según al-Idrīsī, Chinchilla era una ciudad (madīna) mediana, defendida por un castillo y una extensa fortaleza urbana, que estaba rodeada por jardines o almunias y arboledas ${ }^{2}$. Allí nacieron varios personajes entre la segunda mitad del siglo X y la primera del siglo XI que alcanzaron la suficiente relevancia como para figurar en repertorios biográficos como los de Ibn Baškuwāl e Ibn al-Faradīi (Chavarría, 2011, p. 156). De su trama urbana medieval solo podemos identificar en la actualidad la presencia de la alcazaba, en la parte más elevada del cerro; un albacar o espacio abierto en el lado que da al caserío y una medina que se extendía hacia la parte baja del cerro, rodeada de una muralla que partía de la alcazaba (Simón, 2011, pp. 138157).

De la madīna de Chinchilla dependían varios hușūn, situados en los límites del iqlīm, como los de Alpera, Higueruela, Almansa y Carcelén (Fig. 1). Gracias a la arqueología sabemos de la eclosión de estos asentamientos a partir del siglo XI, tal vez en relación con las necesidades defensivas de los habitantes de la región, asociadas a la inestabilidad política de las primeras taifas y, sobre todo, al incremento demográfico de la zona debido a la colonización del campo que de ellos dependía (Jiménez, Simón, 2017). A las localidades que ya existían previamente como Chinchilla, Hellín, Alcaraz, Tobarra y Albacete, se sumarán Ayna, Liétor, Letur, Yeste y Riópar, en las cuencas de los ríos Segura y Mundo; así como los castillos de Alcalá, Jorquera y Ves, en el río Júcar (al noreste de la provincia de Albacete). También los hușūn de
Yakka (Yecla) (Ruiz, 2000, 2009) y de Jumilla (Hernández, Simón, 2015, p. 70), en la actual provincia de Murcia, despegaron en el s. XI. En cualquier caso, estos poblados fortificados de altura permanecerán en el tiempo, experimentando incluso un cierto crecimiento que alcanzó su apogeo en los momentos previos a la conquista cristiana; después de ésta no todos pervivieron y algunos de ellos, como Higueruela y Carcelén, quedaron despoblados.

Antes del desarrollo del poblamiento de la región que manifiestan los husṣūn antes citados, el sector oriental del territorio de Chinchilla parece haber estado dominado por el extenso poblado en altura del Castellar de Meca. A falta de un estudio arqueológico en profundidad, este asentamiento parece responder a un modelo análogo al del Tolmo de Minateda: aprovechan promontorios bien defendidos por la orografía a los que se les dota de refuerzos mediante murallas y torres; cuya ocupación se remonta a la Antigüedad. Este sería el caso igualmente del Santo (Alcaraz) (Simón, Segura, 2013), Peñas de San Pedro (Lorrio, el al., 2014), y otros que se irán sumando por poseer unas características similares según se vislumbra en los trabajos de campo realizados, como La Molata (Letur), Peña Jarota (Nerpio), Mompichel (Chinchilla) y Jorquera. A partir de los materiales recogidos en superficie y en algunas intervenciones puntuales en el Castellar de Meca, parece que podría datarse el abandono del poblado hacia el siglo XI (López, 1985).

A su vez, de aquellos hușūn dependerían administrativamente una serie de pequeños núcleos de población (Figs. 1 y 4), los yacimientos arqueológicos localizados durante las prospecciones intensivas del territorio que hemos venido llevando a cabo (Jiménez, Simón, 2017), que creemos se pueden identificar como alquerías (qurā). Según su emplazamiento, se han podido identificar dos tipos: las que están situadas en altura y las que lo están en llano. Estas últimas conforman el conjunto más numeroso de asentamientos andalusíes de la zona, principalmente en el espacio intermedio entre los ḥuṣūn. Solo están ausentes en el entorno más próximo de la madīna de Chinchilla, que genera a su alrededor un hinterland deshabitado de unos $10-15 \mathrm{~km}$, es 
decir, unas dos o tres horas de camino. Ni las unas ni las otras presentan rastros de fortificaciones comunitarias, elementos que suelen ser característicos de los asentamientos campesinos de carácter segmentario (Barceló, Kirchner, Navarro, 1996, pp. 62 y 63).

Finalmente, son muy abundantes las cuevas refugio ligadas a las actividades ganaderas y silvícolas. Su uso pudo ser estacional y en algunas ocasiones permanente, tal y como lo muestran las construcciones que se levantaron al exterior, ampliando y mejorando las condiciones de vida de sus moradores y relegando al abrigo a una utilización exclusivamente ganadera, como corral. Ejemplo de ello sería la Cueva Negra del Mugrón, entre Almansa y Ayora, al exterior de la cual se construyó una edificación con una crujía compartimentada en tres estancias para el refugio y residencia de sus moradores, y un patio o corral anexo, en el cual se levantaron pequeñas estancias para los aperos, o para las necesidades específicas del ganado, como las parideras. Por su tamaño y ubicación parece lógico suponer que estarían relacionadas con las alquerías próximas del llano, si bien es posible que tuvieran una cierta autonomía funcional. Son especialmente abundantes en la cara meridional de las sierras de Chinchilla, Higueruela y Carcelén. En algunas ocasiones se documentan en la cara norte de los relieves, a cotas de altura considerables, circunstancia que debe de ponerse en relación con el aprovechamiento de los pastos de verano (Simón, Hernández, 2013).

No tenemos referencias que nos permitan identificar la extensión del dominio territorial del hiṣn de Almansa antes de época almohade, aunque sí para la etapa inmediatamente anterior a la conquista cristiana. En ese momento llegará hasta Carcelén, Alpera y Bonete, tal y como queda reflejado en el documento de repoblación de Alfonso X en 1264 "Sepan todos quantos esta carta uieren como nos don Alfonso por la gracia de Dios rey de Castilla, de Toledo, de León, de Gillizia, de Seuilla, de Córdoua, de Murcia, de Jahén e del Algarbe, damos a Almanssa e a los pobladores que y son e que y serán daquí adelante estos lugares que aquí dize por termino. Alpera e Carcelén e Gonet, que los ayan con todos sus terminos e con sus aguas e sus pastos e con sus montes assi commo los auíen en tienpo de los almohades, et deffendemos que nenguno non sea osado de gelo contrallar nin de gelo embargar, ca qual quier que lo fiziesse a el e a lo que ouiesse nos tornaríemos [...]" El ámbito del ḥiṣn de Almansa lindaba, por tanto, con los de Ayora, Jorquera, Chinchilla, Yecla y Villena, por lo que unirá el Valle del Júcar con la Costera Valenciana y los Llanos de Albacete con el Vinalopó.

De esta delimitación, llama poderosamente la atención la adscripción de Carcelén y sus tierras aledañas al ámbito del ḥiṣn de Almansa, pues geográficamente se emplazan en la vertiente septentrional de la Sierra de Higueruela, en su extremo nororiental, en la Sierra Palomeras tradicionalmente vinculada al Valle del Júcar, ya sea a los dominios de Alcalá del Júcar o la Tierra de Jorquera (Pretel, 2011, p. 24), o al Valle de Ayora. Esta relación solo puede tener explicación en las tensiones existentes entre los diferentes iqlìm de la zona que podemos intuir en varios documentos -como la exención del pago de portazgo en 1257 a los repobladores de Requena en "Xorquera e Ayora e Almansa e Vees e Chinchiella [...] que son de parte del regno de Murçia"-, cuyo origen puede situarse en época andalusí, y que tendrán diputas fronterizas que llegarán hasta la constitución de la frontera castellano aragonesa, tanto en época de conquista, con el Tratado de Almizra en 1244, como en su fijación final tras el Tratado de Campillo en 1281.

El resto del iqlīm de Almansa formó parte del alfoz cristiano hasta su segregación por motivos estratégicos, como la incapacidad de los repobladores cristianos de sofocar la rebelión de los mudéjares de 1264-1266, que llevó a la corona castellana a adscribir Alpera a la ciudad de Chinchilla y Carcelén a Jorquera (Almendros Toledo, 2002, p. 57). Finalmente, la constitución del señorío de Montealegre en el siglo XIV dejaría el alfoz de Almansa con una delimitación y extensión muy similar a su actual término municipal (Torres Fontes, 1984, p. 83).

En el territorio castral del hiṣn de Almansa, se documentan tres fortificaciones, la de Almansa, como cabeza del iqlìm, la del Castillo de San 
Gregorio en Alpera y El Torrejón de Carcelén, estas dos últimas claramente vinculadas a las aljamas asentadas en los pequeños valles cuya fertilidad permite el sustento de las comunidades de la zona. Cabe la posibilidad de que exista una alquería con torre en la finca de la Torre Grande, en el extremo oriental del término de Almansa, posteriormente sustituida por una feudal (la Burjaharón de los textos cristianos). También existen dos torres andalusíes en Montealegre del Castillo denominadas como los Pexines en las fuentes de la conquista cristiana; son de cronología imprecisa, pero al menos una de ellas estaría operativa en tiempos almohades, seguramente la del Castillo de Montealegre ( $\mathrm{Si}$ món, 2011, p. 121).

\subsection{El castillo de Almansa}

El actual edificio es el resultado de procesos de construcción, remodelación, derribos, expolio, voladuras y restauraciones, llevadas a cabo a lo largo de más de ocho siglos, de acuerdo con un complejo proceso evolutivo (Simón, 1999). Salvo algunos elementos, la actual fortificación es esencialmente el castillo remodelado por don Juan Pacheco en el siglo XV, de acuerdo con un programa que camufló o suprimió la obra previa de origen andalusí y la mudéjar del señorío de los Manuel (Fig. 2.1).

El castillo se emplaza en la cumbre de un cerro que aflora en el centro de la llanura del Corredor de Almansa. Se trata de un afloramiento de placas calizas, que han quedado dispuestas de forma vertical por el empuje de un domo diapírico, creando un cerro de forma cónica. El Cerro del Águila, como se le conoce, se ubica en el punto donde se encuentra el fondo de valle del Corredor de Almansa con el valle de Ayora, que genera una depresión central sin posibilidad de avenamiento que tradicionalmente se ha inundado de forma estacional, dotando al entorno del cerro de una huerta. Controla el tránsito por todo el territorio, cruzado por caminos reales, veredas y cañadas, que han puesto en contacto a través del Puerto de Almansa y el paso de La Encina las tierras de Levante, tanto de Valencia, en especial la Canal de Navarrés y La Costera, como la de Alicante, por el Alto Vinalopó, con el interior de la Meseta. Por su flanco meridional se llega al altiplano murciano, a través de Yecla y comunica directamente por su extremo occidental con los Llanos de Albacete.

1

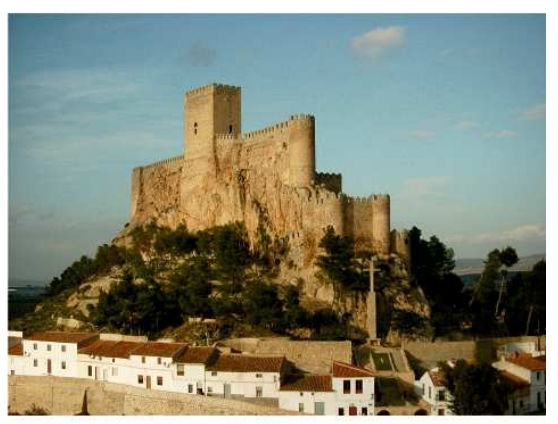

2

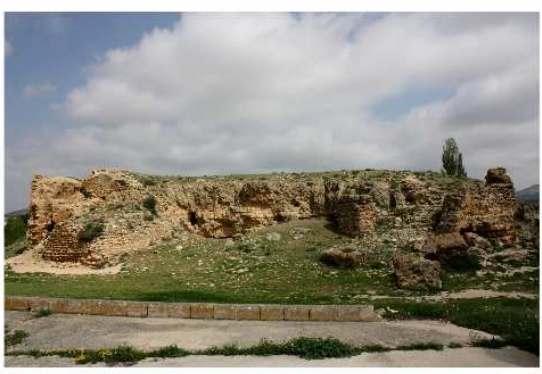

3

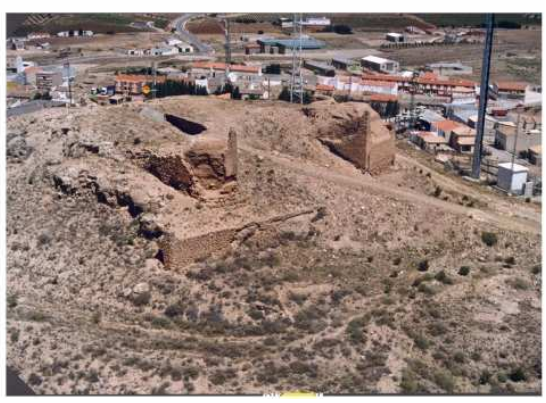

Fig. 2. 1) Castillo de Almansa; 2) Castillo de San Gregorio (Alpera); 3) Castillo de Montealegre.

El castillo de Almansa se desarrolla en época islámica en dos planos, un recinto superior sobre los afloramientos verticales calcáreos, con torres cuadradas en los extremos, un aljibe y una torre en el centro y un recinto inferior, en el lado oriental del cerro, donde se crea un recinto rectangular con torres en las esquinas en cuyo interior existe al menos otro aljibe. El resto, incluido los accesos, han desaparecido o han quedado profundamente alterados en las etapas posteriores, pero todo apunta a una entrada en 
codo (Simón, 2011, p. 105). Toda la obra claramente islámica es el tapial: de calicanto, de argamasa y calicostrado, aparejos que también se usaron de forma generalizada a partir de la conquista y bajo el señorío de los Manuel (Simón, 2011, p. 121), pero no en tiempos de Juan Pacheco, en que ya predominan las mamposterías.

El origen del edificio podría enmarcarse en el contexto del despegue demográfico y económico que experimentó la región en el siglo XI, unido a la inestabilidad política y social del momento fruto de las luchas entre los centros de poder por el territorio y la fortificación de los caminos de al-Andalus. En términos generales, estas circunstancias no variaron durante el siglo siguiente y prácticamente hasta la conquista, por lo que cabe suponer que la fortaleza experimentaría remodelaciones en esas fechas; de todo ello cabe esperar noticia a partir de las excavaciones arqueológicas que se vienen desarrollando durante los últimos años en la terraza inferior, en las que se ha documentado un torreón andalusí, seguramente asociado a la puerta de acceso al edificio.

La fortaleza almanseña encuentra sus paralelos más próximos en los castillos del Valle de Ayora-Cofrentes, especialmente en el Castillo de Ayora, el cual posee un emplazamiento, composición y distribución muy similar a la fortaleza almanseña, si bien su evolución posterior en el marco de las tenencias aragonesas lo transformará intensamente en cuanto a su morfología. Algo similar ocurre con la fortaleza de Yakka (Yecla), con la que comparte la composición en dos recintos y la utilización de lienzos de tapial con desarrollo en cremallera para la constitución de las torres (Ruiz, 2000, p. 191).

\subsection{La Torre Grande o de Burjharón}

La torre se emplaza al pie de la ladera occidental de la Sierra de la Silla, protegida de los vientos dominantes por el Cerro de los Prisioneros, en una especie de collada amplia que se abre tanto hacia el Puerto del Almansa, entre la citada Sierra de la Silla y la Sierra de Almansa, como al paso de La Encina, abierto entre las sierras de la Silla, Timonares y la Oliva o Santa Bárbara, permitiendo el acceso al Alto Vinalopó.
Se trata de un punto estratégico en el nudo de comunicaciones entre Valencia y Alicante y el Corredor de Almansa. La zona se caracteriza por un fondo de valle anegable de forma estacional que fertiliza las tierras de alta productividad agropecuaria, en especial para cereales y arbolado. Está cruzada por varias barranqueras por las que circulan casi de forma ininterrumpida cursos alimentados por numerosas fuentes, posibilitando pequeñas huertas y un área de pastos en las laderas de las sierras que va desapareciendo conforme se gana altura y aparece el bosque de pinar y encinar.

La torre y el caserío que la circunda se remontan al siglo XIV (Fig. 3.2), pero los restos cerámicos localizados en su entorno apuntan hacia la existencia de una alquería en época islámica, similar a la de Bogarra en Caudete, esta última adscrita al hịṣn de Villena (Simón, 2010, p. 91).

La actual Torre Grande será conocida como de Burjarón, Burjaharón, Boriaharón, Bujaharrón, Burxa, Burfçefierón, o Torre de los Catalanes. En la conquista de Almansa entre 1242 y 1243 Burjaharón era una pequeña alquería que el rey Alfonso X el Sabio, por carta fechada en Sevilla el 9 de octubre de 1264, cedía a los almanseños: "[...] por fazerles merçed, dámosles el heredamiento que dizen el Hondón del Almugrón, assí commo va del algibe que está en la carrera de Ayora contra Almansa; e otrossí les damos la alcaría que dizen Boriaharón con todos sus términos.." y quedaba confirmada por otro privilegio real de fecha 15 de febrero de 1265: “..les damos que ayan por término e por aldeas de Almansa para siempre, Alpera, e Carçelén, Bonete, e el heredamiento que diçen el Fondón de Almogrón ansí como va del algibe que está en la carrera de Ayora contra Almansa, e el alcaría que diçen Burxa [...]” (Pretel 1981, p. 182).

La torre puede que sea la citada por Jaime I en la Rúbrica $1^{\mathrm{a}}$ del Libro de los Fueros “...e axí hix a Xerelli e a la Serra de Rua e feneix a Cabriol e al terme de Garamoxén e a la Font de la Figuera, e com hix a Burriharon e de allí Almizrra e al port de Bihar, que parteix terme $a b$ Billena [...]". A finales del siglo XIV, figuraba como señor de la Torre de Burjaharón don 
Jaime de Ayerve, un caballero catalano-aragonés vecino de Almansa (Simón García, García Saez, 2002, pp. 83-88).

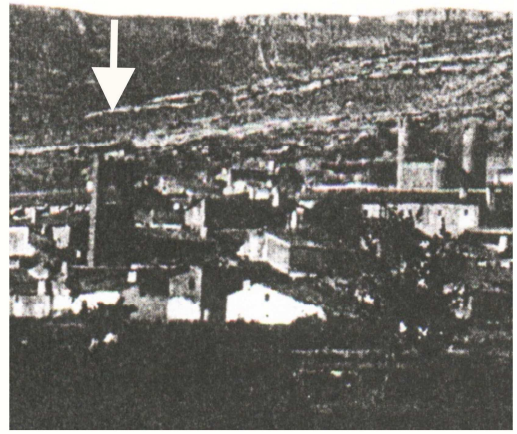

2

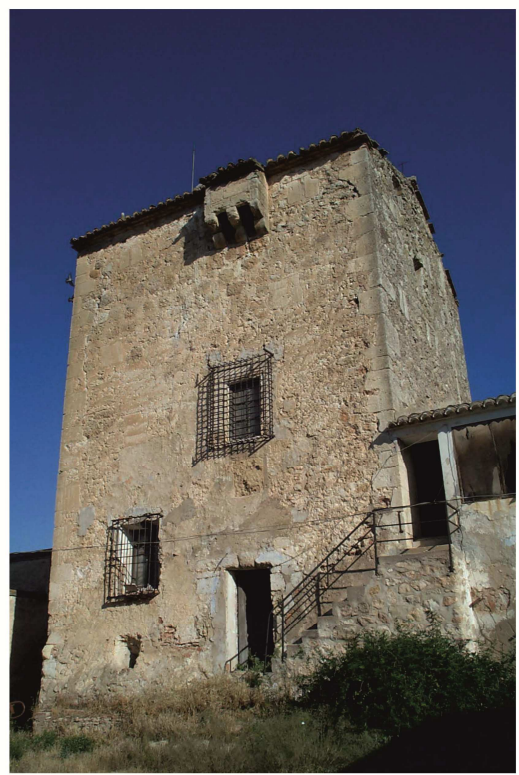

Fig. 3. 1) El Torrejón (Carcelén); 2) Torre de Burjharón (Torre Grande, Almansa).

Por su emplazamiento, la torre era lugar habitual de conflictos locales y entre las coronas de Castilla y Aragón y posiblemente estuvo despoblada durante algún tiempo "[...] dicha Torre de Burjaharón estava en lugar solitario e muy peligroso, donde se recrecía e podrá recrecer munchos peligros, muertes e cativerios por los moros infieles, esto por cabsa e razón que la dicha Torre de Burjaharón non estava poblada de gentes que entendiesen en la defensyón de los cristianos que andavan por los caminos resistiendo a los dichos ynfieles moros [...]" (Rodríguez Llopis, 1984, p. 155) $)^{3}$. Por este motivo, don Jaime de Ayerve consiguió que el rey castellano Enrique III eximiese del pago de tributos reales a quienes se instalasen a vivir en ella, así como que delimitase una dehesa en torno a la misma, medidas destinadas a fomentar el repoblamiento del lugar: "[...] el dicho señor rey don Enrrique e los otros señores susodichos conformaron la dicha dehesa de Burjaharón [...]" (Piqueras, 1987). En relación con este proceso repoblador puede que la vieja torre islámica se reformase y diese paso a la que hoy se conserva, de fábrica y concepción puramente feudal.

\subsection{El castillo de San Gregorio de Alpera}

El castillo de San Gregorio, topónimo con el que se le conoce actualmente, se emplaza sobre un pequeño cerro testigo situado en el centro de la vega de Alpera, que transcurre de oeste a este al pie de las últimas estribaciones de la Sierra de Chinchilla, en su sector más oriental (Simón, 2011, pp. 117-120; Pretel, 2010). Se trata de una vega deprimida, oculta al centro de la llanura que discurre al Sur, enmarcada en el Corredor de Almansa, y con unas condiciones bioclimáticas y medioambientales muy peculiares que han posibilitado el asentamiento de comunidades humanas a lo largo de la historia La vega ha sido explotada agropecuariamente de forma intensiva, con múltiples transformaciones, pero manteniendo un sistema de riego compuesto por sendas acequias, una por cada lado de la vega, que aprovecha las numerosas fuentes del entorno así como las escorrentías de las laderas de la sierra. Después de la conquista, el aprovechamiento hidráulico se vio intensificado entre los vecinos de la aldea a partir de las actuaciones y normas impulsadas por don Juan Manuel, quien amplió la red islámica de riegos de las aguas de Alpera y construyó el curso artificial y la primera presa del pantano de Almansa para dar riego a la vega de San Antón de Almansa, con fines claramente repobladores y con ellos el aumento de rentas (Pereda, 1987, p. 275; Simón, Simón, 2018, p. 119).

La fortaleza se emplaza sobre un pequeño cerro ubicado en la margen derecha del arroyo que le 
da nombre, el cual la bordea y excava su ladera norte, que termina convirtiéndose en una defensa natural (Figs. 2.2 y 5). Actualmente se encuentra amesetado, basculado hacia el sur, y delimitado por las defensas antrópicas o un escarpe de roca de unos pocos metros de elevación; mide $67 \mathrm{~m}$ de oeste a este y $51 \mathrm{~m}$ de norte a sur. Se trata de un recinto poligonal con paños que unen una serie de torres cuadrangulares que se emplazan en el lado más accesible de la fortaleza (Simón, 2011, p. 117). Existen indicios que permiten afirmar que debió de contar con un perímetro completamente cerrado, que los avatares históricos y el uso del edificio como cantera de aprovisionamiento de materiales, en especial de la mampostería y el sillajero, han llevado a la ruina en la mayoría de sus fábricas, permaneciendo solo las de tapial de mampostería, tapial de hormigón y tapial de tierra calicostrada porque no son reutilizables. El interior del recinto está colmatado, aplanado, con múltiples hoyos por el uso de detectores de metales y rebuscas clandestinas; lo más abundante en superficie son los fragmentos de tejas. Abunda también la cerámica andalusí tardía y, en menor medida, la cristiana, especialmente del siglo XIV.

La prospección intensiva del territorio de Alpera ha permitido comprobar la concentración de numerosas alquerías de pequeñas dimensiones a ambos lados de la vega, que se abandonaron durante el siglo XIII, seguramente con motivo de la revuelta de los mudéjares. En uno de los asentamientos centrales existía una muela que fue fortificada con lienzos y torreones de tapial de hormigón en época tardo-andalusí, según demuestran los abundantes materiales cerámicos, y posteriormente ocupada y reacondicionada tras la conquista. Sabemos por los textos que el territorio de Alpera, con su castillo central, sus alquerías y su vega, no era un hiṣn independiente, sino que formaba parte en época almohade del iqlīm o término del hiṣn de Almansa, tal y como queda expuesto en la concesión del fuero de Requena 1262 y el de Cuenca en 1264 a la ciudad de Almansa por el Infante don Alfonso, que cede para su alfoz las tierras de Alpera "assi commo las auien en tiempo de los almohades". No obstante, era reconocido como una realidad territorial que, de hecho, se constituyó en señorío ya inmediatamente después de la conquista. En efecto, Alpera que fue conquistada entre 1242 y 1243 al tiempo que el resto del territorio entre Chinchilla y Almansa, fue donada, junto a Carcelén, por el Infante Alfonso a don Pedro López de Harana, en abril de 1244, comprometiéndose a respetar sus fueros y costumbres, de acuerdo con las cartas otorgadas por el infante.

A diferencia de Almansa, donde al parecer la población islámica huyó convirtiéndose en un concejo real, la mayoría de la población musulmana debió de permanecer en el valle de Alpera, pues en 1264 con motivo de la revuelta de los mudéjares el infante Alfonso solicitó el apoyo de la Corona de Aragón para sofocar la revuelta de Alpera. Jaime I donó al caballero don Guillén de Rocafull el castillo y la villa de Alpera, en un intento de asentar aragoneses a lo largo de la frontera. Ante la incapacidad de Almansa de defender su término, Alpera terminó integrándose en 1265 en Chinchilla. Las consecuencias de dicha acción están aún por valorar, pero todo parece indicar que la población que se mantuvo en la zona, tras el éxodo a Granada y norte de África, se trasladó, seguramente forzada, al emplazamiento actual de Alpera. Puede que también entonces el castillo se arruinara, pues consta que en 1338 se destinaban a las murallas del mismo el importe de las multas a los ganaderos que dañaran la acequia en tierra de Chinchilla (Pretel, 2010, p. 32); en cualquier caso, ya no vuelve a aparecer en las fuentes con motivo de los conflictos de los siglos XIV y XV.

\subsection{El Torrejón de Carcelén}

Se emplazaba en el centro urbano de Carcelén, junto a la vega de la rambla de Fuente Mayor, en la margen izquierda del barranco de Carcelén, que se abre paso en dirección sur-norte en el frente septentrional de la Sierra de Alpera-Carcelén, entre las muelas de Peña Negra y la del General, con el fin de evacuar las aguas hacia el vallejo de San Lorenzo, un pequeño afluente por la margen derecha del río Júcar. Se trata de un pequeño valle transversal que permite comunicar el Valle de Ayora con la parte septentrional 
de la Sierra y las tierras de Chinchilla, ya que por el cañón del Júcar el paso es mucho más dificultoso. Se aprovechan las numerosas fuentes para general pequeñas huertas, siendo el resto explotaciones cerealísticas, pastos y bosques de las sierras de la Solana, Alpera, Carcelén, etc. El tránsito de personas, mercancías y animales queda constatado por la existencia de la Cañada de la Gitana, que discurre de este a oeste por el valle y la Cañada de los Serranos, que cruza de norte a sur.

Aunque en la actualidad se encuentra desaparecido casi por completo, existen evidencias fotográficas y documentales de la existencia de una torre hasta mediados del siglo XX (Fig. 3.1), realizada en tapia, de planta cuadrangular y un alzado trapezoidal, $d e$ "40 varas de/ alto y ocho de ancho". Se situaba en el costado occidental de un castillo del que quedaban "varias murallas arruinadas con muchos baluartes" (Simón, 2010, p. 85). El edificio debió de estar muy abandonado, ya que en las Relaciones de Felipe II, de 1579 , se señala que "en esta villa hay dos pedaços de torres muy viejas y antiguas hechas de tapiero con costra casi caidas e que estan juntos los pedaços y que pareçe ser todo un edificio [...]" (Escrivá, et all., 1998, p. 190) Este tipo de edificios es muy característico de las fortificaciones del siglo XII al XIII, por lo que no podemos saber con exactitud si se trata de una obra islámica; cristiana de las primeras décadas de la conquista, o relacionada con el señorío fundado a mediados del siglo XIV por Sancho Manuel, hijo natural de don Juan Manuel. Cabe señalar que, por la descripción, parece tener muchas similitudes, al menos en sus elementos y composición, al edificio que levantó Sancho Manuel en Montealegre del Castillo. A diferencia de éste, el castillo de Carcelén no se construyó sobre ninguna elevación, sino prácticamente al pie de la ladera, en medio del caserío medieval, por debajo incluso del emplazamiento del castillo señorial que se erigió a mediados del s. XV (Simón, 2011, pp. 80-84); un emplazamiento que presenta fuertes analogías con el del también desaparecido castillo de Letur.

Se tienen noticias de Carcelén desde la conquista del hiṣn de Almansa entre1242 y 1243 por el infante Alfonso y el maestre de la Orden de Santiago Pelay Pérez Correia. Fue donada, junto a Alpera, por el Infante Alfonso a don Pedro López de Harana, en abril de1244, comprometiéndose a respetar sus fueros y costumbres, de acuerdo con las cartas otorgadas por el infante. En 1264 el Infante Alfonso la adscribió al concejo de Almansa; sin embargo, la revuelta mudéjar de ese año que el concejo de Almansa es incapaz de controlar, supondrá que en 1266 Alfonso X adscriba Carcelén a Jorquera, para posteriormente integrarla en el señorío de Villena, bajo el mando de los Manuel. En 1330 Don Juan Manuel, cedió a su hijo natural Sancho Manuel un señorío dentro de sus tierras, compuesto por las tierras de Montealegre y Carcelén, que tenían en común el control y paso de la ruta ganadera de Los Serranos, vía que une la serranía conquense con las tierras del Campo de Cartagena y el mantener una importante población mudéjar. La Guerra de los Dos Pedros entre las coronas de Aragón y Castilla, supuso la huida de los Manuel de Carcelén a territorio aragonés, circunstancia aprovechada por el concejo de Jorquera para recuperar sus dominios. Finalizada la contienda Constanza Manuel mantendrá casi cuarenta años un pleito para recuperar sus derechos, lo cual ocurrirá finalmente en 1398, según registra un documento en el que se reconoce el carácter mudéjar dela población (Simón, 2011, pp. 85-87).

\subsection{El castillo de Montealegre y la torre de Pexín}

En Montealegre se han documentado dos construcciones, seguramente defensivas, que se remontarían a época andalusí: algunos muros reaprovechados en el castillo bajomedieval de Montealegre y una estructura en forma de torre poligonal en los Castellares. De alguna manera, estos edificios serían los que aparecen en la documentación medieval como la Torre Pechín, Pexín, Rexín, Regín (Torres 1983, pp. 90), aunque no es posible determinar si se refiere a una de ellas, estando la otra en ruinas o a las dos, cuando en 1244 el infante Alfonso dona al caballero santiaguista Sancho Sánchez Mazuelo "la villa y castillo de Caudete, cerca de Bugarra, y la torre de Pechín, que es entre Yecla e Chinchella". 
El castillo se emplaza en la parte alta del conjunto montañoso conocido como Los Algezares, que delimita por el norte el pasillo que se abre en el citado cerro y la Sierra de Cueva Alta o Arabinejo, donde se sitúa los Castellares. Se trata de un conjunto de alineaciones montañosas entre las que se abre camino tanto el avenamiento hídrico de la zona, especialmente la Rambla Salada, que parte de Bonete y llega hasta Yecla, en el altiplano murciano, y los tradicionales caminos, donde destaca el paso de la Vía Augusta, la Vereda de los Serranos y el Camino Real de Madrid a Alicante. Esta circunstancia ha motivado una constante e intensa ocupación humana que ha dejado vestigios tan significativos como los abrigos rupestres del Arabí, el santuario ibérico del Cerro de los Santos, la necrópolis del Llano de la Consolación y un número muy elevado de pequeños poblados, villas, alquerías, caseríos y núcleos de viviendas por todo el territorio. La zona se ha caracterizado por una explotación de huerta en los amplios márgenes de la rambla de Agua Salada, irrigada mediante pozos y norias, amplios campos de cereal, vid y almendro en los llanos y zonas de pastos en las lomas, cerros y sierras de la zona

La torre de los Castellares es una construcción de planta octogonal, aunque su excavador J. Zuazo (1916) la describiese como hexagonal. $\mathrm{Su}$ factura es de tapial de mampostería encofrada (Simón, 2011, pp. 126, 127). La única cara interior conservada mide 3'30 m de largo por $0,65 \mathrm{~m}$ de ancho, lo que daría una cara exterior de 4,65 m de largo. En las excavaciones del citado autor se recogió una jarrita de dos asas con vidriado parcial e irregular en verde oscuro, tres candiles de pellizco de vidriado en verde claro, fragmentos de tinajas con decoración estampillado, una jarrita con decoración de óxido de hierro, cerámica "policromada" -posiblemente de cuerda seca total-, cerámica esgrafiada, ataifores, dos pequeñas orzas esmaltadas enmelado, y dos monedas de oro. De todo ello, tan solo se conservan en el Museo de Albacete las dos orcitas y la jarrita esmaltada en verde oscuro, el resto ha desaparecido. La primera noticia de la torre se tiene cuando en 1244 el infante Alfonso dona al caballero santiaguista Sancho Sánchez Mazuelo "la villa y castillo de
Caudete, cerca de Bugarra, y la torre de Pechín, que es entre Yecla e Chinchella". Torres Fontes señala que en 1253 Sancho Sánchez intenta la cesión de sus posesiones a la Orden de Santiago, hecho que se frustra y que le lleva a vender sus posesiones a don Gregorio y a su esposa doña Gueralda de Santa Fe, en 1256. Nada sabemos de la torre con posterioridad hasta que se crea, en la cuarta década del siglo XIV, el señorío de Montealegre y Carcelén, donde ha desaparecido el nombre de Pexín y aparece por primera vez el de Montealegre, La concesión de don Juan Manuel a su hijo natural Sancho Manuel debió de ser un territorio "pequeño, no cultivado, deshabitado y en ruinas" (Torres Fontes, 1983), en especial tras la revuelta mudéjar y las luchas entre las coronas cristianas. En las Relaciones de Felipe II de 1579 se contesta "que ha habido unos edificios que vulgarmente se llama villares, que están en la dehésa que tiene declarada, y que han oído decir a sus mayores, que en los villares había una población, que se llamaba Pechín y se había desplomado por ser pueblo muy enfermo" (Rodríguez, Cano, 1987, p. 242). Hay que tener presente que las ruinas visibles están en una zona muy baja del terreno, propicia al encharcamiento de las aguas de la Rambla de Aguas Saladas, circunstancia que favorece la propagación de enfermedades palúdicas, características de estos ambientes; de hecho, la zona, una vez emplazada la población al pie del castillo, fue destinada a dehesa comunal.

El castillo de Montealegre posee dos recintos, uno en la parte superior, de tendencia cuadrangular, dispuestos los elementos y crujías en torno a un patio central donde se emplaza un aljibe, y un recinto exterior, en una cota inferior, que cierra parte de la ladera meridional, occidental y parte de la septentrional (Fig. 2.3). La torre del castillo es de planta cuadrada, realizada en tapial de mampostería y será el núcleo y elemento de partida del cual surge el castillo feudal en el siglo XIV. Como decíamos, tras las excavaciones arqueológicas efectuadas en el castillo se pudo comprobar la existencia en el ángulo noroeste del recinto de algunos muros de mampostería tomada con argamasa, asociados a niveles andalusíes que se podrían remontar a los siglos XI-XII. Estas construcciones habían sido 
en parte reutilizadas por el edificio bajomedieval.

El castillo señorial parece que se remonta a los primeros años de 1330, cuando en la concesión don Juan Manuel, señor de Villena, concedió a su hijo natural Sancho Manuel las tierras de Montealegre y Carcelén, dos territorios del antiguo hișn de Almansa. Sancho Manuel encuentra en las tierras de Montealegre el caserío de Pechín, un pequeño núcleo habitado de época árabe, asentado en lo que hoy se conoce como Los Castellares que ya había sido ocupado en épocas ibérica y romana. Aquí se alza lo que parece una torre de planta hexagonal, realizada en hormigón con mampostería, que no servía para las funciones residenciales y de representación que demandaba un señor feudal en el siglo XIV, lo que llevó a Sancho Manuel a elegir una elevación cercana en la que se alzaba una fortaleza andalusí, más adecuada como nuevo emplazamiento para su casa, castillo y puebla a su alrededor. El edificio se construyó en su estructura principal, tal y como nos ha llegado, en la cuarta década del siglo XIV, con materiales de bajo coste, empleando técnicas mudéjares, es decir, la base de mampostería, las paredes de tapial de tierra con enlucidos de yeso y cubierta de vigas de madera y teja. La Guerra de los Dos Pedros en la primera mitad del siglo XIV, supuso la huida de los Manuel de Montealegre a territorio aragonés, circunstancia aprovechada por el concejo de Chinchilla para ampliar sus dominios. Pedro I de Castilla confirmó en 1364 la donación o la venta de las tierras de Montealegre, mandando la demolición de la fortaleza para eliminar puntos desde donde atacar a sus fuerzas. La orden real fue cumplida con saña por las tropas del concejo de Chinchilla, destruyendo las tapias hasta la base de mampuesto. La parte más afectada es la de la fachada suroeste, entre las torres donde se ubicaba la puerta de acceso al recinto militar sobre las que se situaban las estancias señoriales, siendo incendiadas al igual que la parte alta de las torres, lo que supondrá un pago adicional en las indemnizaciones que Constanza Manuel recibirá del concejo de Chinchilla en 1411.

\section{Síntesis: el poblamiento islámico en el Co- rredor de Almansa}

A juzgar por los elementos constructivos que se han conservado hasta la fecha y los materiales arqueológicos en documentados, la historiografía tradicional se ha inclinado por datar la fortaleza islámica de Almansa en un periodo que estaría entre las segundas taifas, mitad del siglo XII, bajo el gobierno de Muḥammad ibn Sa'ad ibn Mardanīš, y el dominio almohade, dentro de la dinámica de construcción de fortificaciones que identificó Rafael Azuar (1997, p. 15; 2016, p. 189) en el valle del Vinalopó, área a la cual Almansa está fuertemente vinculada en la Edad Media. Según este investigador, será con los almohades, en la segunda mitad del siglo XII, cuando se produzca en la zona una verdadera "eclosión fortificadora" (Azuar, 2016, p. 137), consolidando o asentando poblaciones en lugares estratégicos y, sobre todo, con capacidad productiva como para mantener un grupo humano amplio y con posibilidades de crecimiento. Esta circunstancia permitiría un control efectivo del territorio y una explotación del mismo que llevaría a poder recabar unos impuestos con los cuales mantener el aparato militar y administrativo de un estado que fuese capaz de hacer frente a la cada vez mayor presión de los reinos cristianos, al tiempo que impediría con la presencia militar el avance de estos reinos. Las características de estas fortalezas, con independencia de las particulares obligadas por el soporte geológico o la intencionalidad de sus constructores son muy similares: estructuras sólidas y compactas, con apenas aberturas y ausencia de decoración, construidas mediante la técnica de tapial, un encofrado de madera relleno de mortero o tierra y accesos en codo (Azuar, 1997, p. 18).

Desde el punto de vista de la técnica constructiva, sin embargo, los avances en la investigación de los últimos años no permiten adscribir automáticamente las fábricas de tapial de hormigón a época almohade en el levante de al-Andalus, puesto que la arqueología viene demostrando que estos aparejos eclosionan a fines del siglo XI y se continuaron empleando con profusión durante los siglos siguientes, incluso a lo largo de la Baja Edad Media cristiana. Así, por 
ejemplo, claramente posteriores a la conquista serían los recintos fortificados y torres levantados con tapial de hormigón en Socovos, Isso, Taibilla o Sierra, todo ellos en la provincia de Albacete, o el propio castillo de Montealegre que hemos descrito más arriba. En cualquier caso, estas fábricas, algunas de las cuales han llegado en pie hasta nuestros días, no necesariamente han de ser las fundacionales, pues en algunos casos en los que se han podido llevar a cabo intervenciones arqueológicas cuidadas, se ha podido comprobar que frecuentemente los tapiales de hormigón forraban o amortizaban obras más antiguas de mampostería y tapia de tierra que sí se podrían remontar a época andalusí, como ha sucedido, por ejemplo, en Alhama de Murcia, Caudete, Taibilla, Sierra o Siyāsa (Cieza, Murcia). Por todo lo expuesto, para poder valorar apropiadamente el significado de estas fortalezas es necesario examinarlas en el contexto de le evolución histórica del poblamiento de la región.

En torno a estos ḥuṣūn se desarrolló toda una serie de asentamientos rurales o qurā ( $\mathrm{pl}$. de qarya, alquería) de tamaño y emplazamiento variables, aunque existen algunas pautas que podemos examinar (Fig. 1). En primer lugar, llama la atención el espacio vacío en torno al núcleo de población más importante, Almansa, debido seguramente a que concentraba toda la población cuyo espacio productivo estuviera situado a una distancia relativamente amplia; fenómeno que también pudimos detectar en Chinchilla y Siyāsa, por ejemplo. El patrón de poblamiento es sensiblemente diferente en Alpera, donde hay un alto número de alquerías a lo largo de una vega angosta. Finalmente, también se aprecia la articulación del poblamiento en torno a la cañada de los Serranos, que separa las alquerías en dos grupos, quizás unas adscritas al iqlìm de Almansa y las otras al iqlìm de Chinchilla.

Estos asentamientos carecen en general de elementos defensivos y, aunque unos pocos están enclavados en puntos elevados, se emplazan en su mayoría en el llano; de hecho, el número de las que conocemos en esta situación es cada vez mayor, pese al sesgo de la información propor- cionada por las prospecciones debido a que estas se conservan peor que las emplazadas en altura por causa de las intensas tareas agrícolas de las últimas décadas (Fig. 4).

1

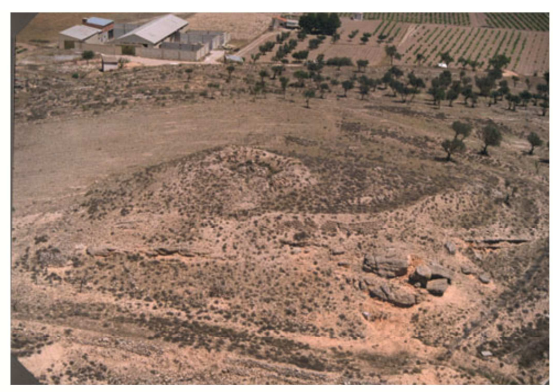

2

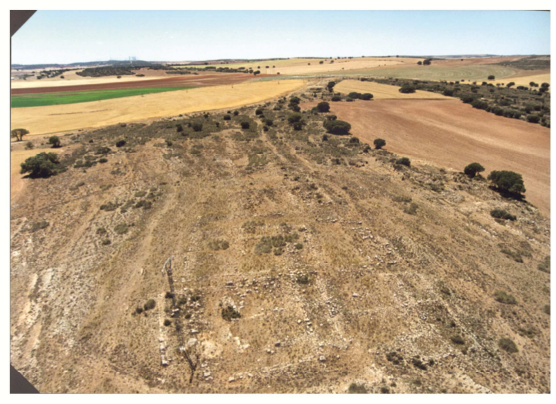

3

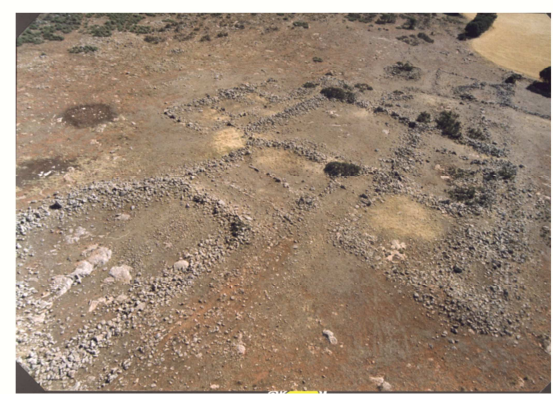

Fig. 4. 1) El Castellar (Montealegre); 2) Alquería El Villar del Bachiller (Chinchilla); 3) Alquería de La Toyosa (Chinchilla).

Dado que el entorno apenas ha estado habitado históricamente, los materiales constructivos de los yacimientos localizados no han sido reutilizados, por lo que presentan un estado de conservación tan bueno que es posible en muchos casos levantar planimetrías generales en las que se pueden registrar los perímetros de manzanas y edificios, e incluso a veces la distribución interna de las casas. Algunos parecen haber contado con escasamente una decena de casas, 
como por ejemplo La Toyosa (Fig. 4.3); mientras que otros debieron de alcanzar las 40 o 50, como sucedía en Los Villares del Bachiller (Chinchilla) (Fig. 4.2). Todos ellos muestran unas características comunes como su situación en tierras que aún hoy en día, pese a la mecanización del campo, son espacios baldíos, bien por situarse sobre lomas donde el afloramiento del sustrato rocoso y la escasez de suelo las han hecho inservibles para el cultivo, bien por tratarse de zonas de monte bajo, tradicionalmente dedicado al pastoreo. En general, presentan unas condiciones geográficas que no permitían la existencia de un regadío tradicional más que de forma testimonial; son excepcionales los que están situados junto a pequeñas vegas, como el de Tobillos en Alpera (Simón, 2011, pp. 167266), que pudieron explotar espacios agrícolas irrigados de escasa extensión y sin posibilidades de ampliación debido al escaso caudal disponible y a un sustrato geológico de las posibles áreas de expansión carente de suelos aptos para el cultivo. Casi todos quedaron abandonados a mediados del siglo XIII, con motivo de la conquista castellana. En cuanto a su distribución en el iqlīm de Almansa podemos apreciar que aparecen agrupadas geográficamente en torno a las cañadas o las vegas de la zona, en conjuntos de 5 a 8 asentamientos que incluyen alquerías y cortijos compuestos por solo una o dos viviendas, que quizás pudieron compartir algún tipo de establecimiento comunitario, como un oratorio o un refugio en algún punto bien protegido para las ocasiones en que hubiera peligro. En torno del hiṣn de Almansa se produce un emplazamiento a una cierta distancia, normalmente una jornada de viaje a pie o caballería, mientras que, en los casos de los huusuun, como los del Torrejón de Carcelén y el Castillo de San Gregorio, lo hacen a escasa distancia para lograr su refugio o protección inmediata. En los relieves montañosos del hiṣ̣n de Almansa son muy abundantes las cuevas refugio ligadas a las actividades ganaderas y silvícolas, especialmente en el macizo de El Mugrón de Almansa, Los Carasoles del Bosque de Alpera y los relieves de Montealegre, Bonete y la Sierra de la Oliva de Caudete. Su uso pudo ser estacional y en algunas ocasiones permanente, tal y como lo muestran las construcciones que se levantaron al exterior, ampliando y mejorando las condiciones de vida de sus moradores y relegando al abrigo a una utilización exclusivamente ganadera, como corral y parideras.

Desgraciadamente, las fuentes escritas no aportan información alguna acerca de este poblamiento y el recurso de la toponimia es también limitado, puesto que la zona quedo casi totalmente desprovista de población a partir de mediados del siglo XIII, lo que debió de ocasionar la desaparición de la mayor parte de los nombres geográficos. Los escasos datos existentes fueron analizados por Robert Pocklington (2010), quien demostró la inexistencia de nombres de origen tribal árabe o bereber; la mayoría designan elementos del paisaje, accidentes geográficos o apelativos individuales. Unos pocos resultan algo más informativos, pues aluden a las características o naturaleza del asentamiento, como Bete (Higueruela) del árabe bayt "casa"; o Zucaña (Almansa), que remontaría al diminutivo sukayna del vocablo sakan "vivienda, morada"; mientras que el nombre del pago de Alcoraya, ubicado $2,5 \mathrm{~km}$ al noreste de Caudete, procede claramente del árabe al-Qurayya "la pequeña alquería", diminutivo de qarya "alquería, caserío".

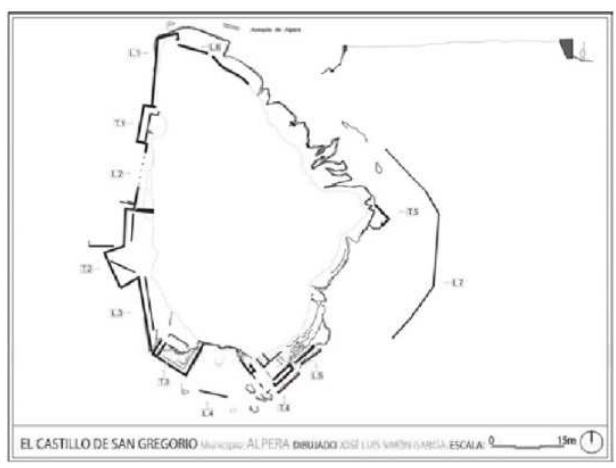

Fig. 5. Plano y sección del castillo de San Gregorio (Alpera).

En esta región, la producción agropecuaria ha estado conformada de forma secular por los cultivos de secano -cereales, leguminosas, olivo, almendro y vid-, y la ganadería extensiva -ovejas, cabras, así como ganado vacuno y équido-, estos 
dos últimos asociados a las tareas de tiro y labranza ${ }^{4}$. Efectivamente, la mayoría de los asentamientos están situados lo más próximo posible a las seculares rutas pecuarias que cruzan la comarca y que conocemos por la documentación posterior a la conquista. En el caso de las alquerías dependientes del hisn de Almansa, el emplazamiento de la mayoría se sitúa en las inmediaciones de ramales de cañadas o cordeles, como la Cañada Real de Andalucía y la Cañada de los Serranos, empleadas en época islámica, quizás en trayectos más locales o comarcales, pero claramente en relación con las necesidades de pastos a lo largo de las diferentes estaciones del año. En este sentido, conviene tener en cuenta que existen pruebas que demuestran la existencia del pastoreo transterminante en al-Andalus e incluso de la trashumancia, si bien esta actividad no estaba organizada como en la Castilla bajomedieval (Lagardère, 1993, p. 459; Ibn 'Iyāạ, 1998, p. 74). Por ejemplo, entre las sentencias jurídicas del cadí 'Iyāọ hay una muy interesante pues hace referencia a un grupo de pastores que moran en una alquería (qarya) junto con sus familias y otros que debían de ser agricultores; la cuestión es que esos pastores pretenden no participar en el pago del sueldo del imām de la mezquita, al igual que el resto de los habitantes censados, porque afirman que no permanecen en la alquería más que unos pocos días pues el resto del tiempo lo pasan fuera con sus ganados. Por consiguiente, parece posible suponer que, al igual que en épocas más recientes, los asentamientos andalusíes sustentarían su economía en la agricultura de secano y en la ganadería, especialmente ovina y caprina, que abastecería de lana a los talleres para la elaboración de paños de la región acreditados por las fuentes árabes. A mediados del siglo XII, al-Idrīsī destaca a Chinchilla, junto con Cuenca, como centro productor de tapices o mantas (wațā) de lana "que no podrían imitarse, circunstancia que depende de la calidad del aire y de las aguas" (Idrīsī, 1974, p. 185). Esta noticia aparece también en la obra del geógrafo e historiador oriental al-Hiimyarī (s. $\mathrm{XV}$ ), quien refiere que "de esta localidad reciben el nombre algunos tapices llamados "de Chinchi1la", pues es en ella donde se fabrican" (1938, p. 116); más adelante confirma la noticia al hacer re- ferencia a Iniesta, pues dice que ésta es un "castillo de al-Andalus a unas dos jornadas de Chinchilla, la localidad donde se fabrican tapices" (1938, p. 197). A partir de estas referencias, es posible suponer que sea precisamente Chinchilla el lugar cercano a Tudmīr en donde, en el siglo XI, al-'Udirī señalaba la fabricación de "maravillosos talleres de alfombras y tapices o cobertores" (1965, p. 9).

En resumen, estamos ante alquerías o aldeas campesinas, puesto que no existe rasgo alguno que permita deducir que se trate de establecimientos aristocráticos o estatales. Tampoco identificamos elementos colectivos de producción, custodia o protección (sistemas hidráulicos comunitarios, graneros comunales o hușūn-refugio) ni toponimia gentilicia que permitan suponer que los pobladores de esos asentamientos formaban parte de grupos clánico-tribales. Parece, por tanto, que podrían estar habitados por familias o grupos familiares reducidos, seguramente organizados vecinalmente de acuerdo con el modelo social que, como vimos, parece predominar en este momento. Al igual que los rahales murcianos y las almunias aristocráticas del campo de Lérida, la actividad económica principal de los habitantes de estos asentamientos sería la agricultura de secano y la ganadería, aunque en este caso no estaríamos ante terratenientes urbanos sino ante modestos campesinos, a juzgar por la ausencia de construcciones suntuarias. La colonización y explotación de estos campos sería una alternativa de carácter secundario pues comportaba elevados riesgos y escasa rentabilidad al estar expuesta a crisis por malas cosechas en función de la meteorología; a diferencia del regadío, que sería la opción campesina preferente dado que los peligros asociados eran sensiblemente menores. Lo mismo sucedía con la ganadería, que en la etapa preindustrial registraba siempre altas mortandades por la amenaza constante de las epidemias (Newfield, 2013, p. 77). Las huertas se limitaron a los estrechos márgenes de vegas abastecidas por manantiales, siendo la de Alpera la de mayor tamaño de la comarca, con $6 \mathrm{~km}$ de largo y unos $70 \mathrm{~m}$ de anchura media a ambos lados de un cauce cuyo exiguo caudal, junto a los condicionantes orográficos, no permitieron desvíos o canalizaciones mediante paradas o azudes, ni elevaciones con norias y aceñas. Por consiguiente, creemos que la 
ocupación y explotación de estas tierras escasamente productivas y sin recursos hídricos significativos (Simón y Simón, 2018), debe interpretarse como evidencia de los movimientos de grupos de campesinos hacia tierras anteriormente yermas, de la necesidad de vivificar y explotar espacios poco favorables una vez que los mejores ya estaban ocupados y, en última instancia, del incremento generalizado de actividad agrícola en este periodo. Somos conscientes de los límites que impone el alcance regional del estudio y que será necesario que futuros proyectos permitan matizar, corregir o ampliar las conclusiones expuestas.

\section{Notas}

${ }^{1}$ Acerca de la evolución del topónimo de Chinchilla desde su origen prerromano véase Chavarría, 2011.

2 Al-Idrīsīi, 1866-1968, pp. 175, 195 (texto árabe); pp. 210, 237 (traducción francesa).
${ }^{3}$ Apéndice documental IV. 1428-X-19 Carta de privilegio y confirmación otorgada por Juan de Altarriba, alcalde de las mestas del obispado de Cartagena, a favor de Alfonso Ximenez de Pina, vecino de Almansa, confirmándole la posesión de la dehesa de Burjaharon (A. Real Chancillería de Granada, Cab. 3, leg. 1185, $n^{\circ} 1$. Traslado del siglo XVI).

${ }^{4}$ En la estadística de usos del suelo en la década de 1980-1990 aportada por el Ministerio de Agricultura, figura que tan solo se dedicaba a la explotación del suelo en forma de huerta el $0,16 \%$ de la comarca, incluyendo los espacios irrigados mediante sistemas de extracción moderna, por lo que la superficie de regadío debió de ser aún bastante menor en época islámica. Datos obtenidos del Ministerio de Agricultura, Alimentación y Medio Ambiente a través de GEOPortal.

\section{Bibliography}

Al-Himyarī. (1938). Kitāb al-Rawḍ al-mi ‘țār, Lévi-Provençal, E., ed., trad., french, La Péninsule Iberique au MoyenÂge, Brill, Leiden.

Al-Idrīsī. (1866). Nuzhat al muštaq, Dozy, R.; de Goeje, M.J., ed., trad., french, Description de l'Afrique et de l'Espagne . Leiden, (reimp. 1968).

Al-Idrīsī. (1974). Geografía de España, Anubar, Valencia.

Almendros Toledo, J.M. (2002). "Configuración del término de Jorquera por un privilegio alfonsino", in Pretel Marín, A., coord., II Congreso de Historia de Albacete. Vol. II. Edad Media, pp. 57-62.

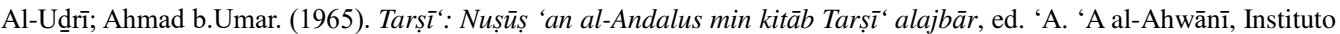
Egipcio de Estudios Islamicos, Madrid. Trad parcial y estudio de Molina, E. (1972). "La cora de Tudmīr según alUd̆īī (s. XI). Aportaciones al estudio geográfico-descriptivo del SE peninsular", Cuadernos de Historia del Islam, IV, vol. Monográfico.

Azuar Ruiz, R. (1997). "Fortificaciones de taifas en el Sharq al-Andalus", Castells, 7, pp. 11-22.

Azuar Ruiz, R. (2006). Castillos, ciudades y campesinos en el Sharq al-Andalus, Alicante.

Barceló, M.; Kirchner, H.; Navarro, C. (1996). El agua que no duerme. Fundamentos de la arqueología hidráulica andalusí, El legado andalusí, Granada.

Carmona, A. (2009). "El sur de Albacete y los emplazamientos de lyuh", Al-Basit, 54, pp. 5-27.

Escrivá, C.; Nicolau, R.; Sánchez, L. (1998). "La arqueología en el término de Carcelén”, in Gómez Molina, J.J., El desvanecimiento de la memoria. Autorretrato de una comunidad rural, Junta de Comunidades de Castilla-La Mancha, pp. 189-193.

Chavarría Vargas, J. A. (2011). Cuando Castilla-La Mancha era Al-Andalus: geografía y toponimia, Ciudad Real, pp. 145-168.

Gutiérrez Lloret, S. (1996). La Cora de Tudmir. De la Antigüedad tardía al mundo islámico. Poblamiento y cultura material, Madrid.

Hernández Carrión, E.; Simón García, J.L. (2015). El castillo de Jumilla. Historia de un centinela, Jumilla.

Ibn 'Iyāḍ. (1998). Mậāhib al-ḥukkām fī nawāzil al-aḥkām (La actuación de los jueces en los procesos judiciales), Serrano, D., trad., est., CSIC, Madrid.

Jiménez Castillo, P.; Simón García, J.L. (2007). "El poblamiento andalusí en las tierras de secano: el área sudoriental de La Mancha (ss. XI-XIII)”, Al-Qantara, XXXVIII 2, pp. 215-259.

Lagardère, V. (1993). Campagnes et paysans d'Al-Andalus (VIII ${ }^{e}-X V^{e}$ s.), Maisonneuve et Larose, París. 
López García, I. (1985). “Cerámicas islámicas del Castellar de Meca”, Sharq al-Andalus: Estudios mudéjares y moriscos, 2, pp. 183-189.

Lorrio Alvarado, A.; Simón García, J.L.; Sánchez de Prado, M. ${ }^{a} D$. (2014). "La Peña del Castillo (Peñas de San Pedro, Albacete): de oppidum ibérico a fortaleza cristiana", Lvcentvm, XXXIII, pp. 73-112.

Abid Mizal, J. (1989). Los caminos de al-Andalus en el siglo XII: según "Uns al muhâ̂ wa-rawḍ al-furâ̂" (solaz de corazones y prados de contemplación), Consejo Superior de Investigaciones Científicas, Madrid.

Newfield, T.P. (2013). "Early Medieval Epizootics and Landscapes of Disease: The Origins and Triggers of European Livestock Pestilences, 400-1000 CE”, in Kleingartner, S., ed., Landscapes and Societies in Medieval Europe East of the Elbe, PIMS, Toronto, pp. 73-113.

Pereda Hernández, M.J. (1987). "Pugna entre los concejos de Chinchilla y Almansa por las aguas de Alpera", in I Congreso de Historia del Señorío de Villena, Instituto de Estudios Albacetenses, pp. 275-282.

Pocklington, R. (2010). "Toponimia Ibérica, Latina y árabe de la provincia de Albacete”, Al-Basit, 55, pp. 111-167.

Ponce Herrero, G. (1989). El Corredor de Almansa: estudio geográfico, Albacete.

Piqueras García, R. (1987). “La Torre y la Dehesa de Burjaharón”, Revista de Fiestas Mayores, s.p.

Pretel Marín, A. (1981). Almansa medievaluna villa del señorío de Villena en los siglos XIII, XIV y XV, Almansa.

Pretel Marín, A. (2010). "Poblamiento e hidráulica en Alpera y su entorno: de la alquería islámica a la villa cristiana", Al-Basit, 55, pp. 5-46.

Pretel Marín, A. (2011). Conquista y poblamiento del Júcar de Albacete, Edición conmemorativa del VIII centenario de la primera conquista, Caja Rural de Casas Ibañez.

Rodríguez de la Torre, F.; Cano Valero, J. (1987). Relaciones geográfico-históricas de Albacete (1786-1789) de Tomás López, Instituto de Estudios Albacetenses.

Rodríguez Llopis, M. (1984). "Expansión agraria y control de pastos en tierras albacetenses durante el siglo XV", in I Congreso de Historia de Albacete, I.E.A., Albacete, tom. II, pp. 155-180.

Ruiz Molina, L. (2000). "Ḥiṣn Yakka. Un castillo rural de Šarq al-Andalus. Siglos XI al XIII. Excavaciones Arqueológicas en el Cerro del Castillo de Yecla (1990-1999)", Revista de Estudios Yeclanos, 10, vol. Monográfico.

Ruiz Molina, L. (2009). "Yakka: un castillo de Šarq al-Andalus en los siglos XII y XIII. Aproximación histórica al poblamiento almohade en Yecla (Murcia)", Tudmīr, 1, pp. 77-138.

Simón García, J.L. (1999). "El Castillo de Almansa: pasado y futuro de un edificio histórico", in II Jornadas de Estudios Locales, Almansa, pp. 99-144.

Simón García, J.L. (2000). "Castillos y torres medievales en el corredor de Almansa (Albacete)”, in Oliveira, J.V., coord., III Congreso de Arqueología Peninsular. Vol. 7. Arqueología da Idade Média da Península Ibérica, Vila Real, pp. $227-242$.

Simón García, J.L. (2002). "Estructuras defensivas medievales en el corredor de Almansa (Albacete)”, in Pretel Marín, A., coord., II Congreso de Historia de Albacete. Vol. II. Edad Media, Instituto de Estudios Albacetenses, Albacete, pp. 31-42.

Simón García, J.L. (2007). "Arqueología de la Arquitectura como paso previo a la gestión de castillos y fortalezas: los casos de Chinchilla, Almansa y Caudete (Albacete)", in La gestión del Patrimonio Histórico Regional: homenaje a Victoria Cabrera Valdés, vol. 1, pp. 253-266.

Simón García, J.L. (2011a). "El poblamiento islámico en el Corredor de Almansa y las tierras de Montearagón: Los andalusíes olvidados", in Las raíces de Almansa: desde los orígenes del poblamiento hasta el fin de la Edad Media. XVI Jornadas de Estudios Locales, Ayuntamiento de Almansa, Almansa, pp. 169-266.

Simón García, J.L. (2011b). Castillos y torres de Albacete, Instituto de Estudios Albacetenses “Don Juan Manuel”, Albacete.

Simón García, J.L. (2016). "Sax, Salinas, Villena y Caudete en el sistema de fortificación de la frontera medieval”, in Ponce Herrero, G., coord., La conquista cristiana del Valle del Vinalopó: territorio y fortalezas, Alicante, pp. 351-376.

Simón García, J.L.; García Saez, J. (2002). “Arquitectura Gótica en Almansa, testigos de una época épica”, in IX Jornadas de Estudios Locales de Almansa. Arquitectura religiosa en Almansa, pp. 23-124.

Simón García, J.L.; Hernández Carrión, E. (2013). “Trashumancia y arquitectura de piedra en seco en Albacete”, Zahora, 57, pp. 67-89.

Simón García, J.L.; Segura Herrero, G. (2011). "El poblamiento tardoantiguo y emiral en la Sierra de Alcaraz (Albacete)", Antigüedad y cristianismo: Monografías históricas sobre la Antigüedad tardía. Ejemplar dedicado a: Mozárabes. Identidad y continuidad de su historia, 28, pp. 327-353.

Simón García, J.L.; Simón Oliver, F. (2018). “Agua y poblamiento en el Sureste”, Murgetana, 138, pp. 101-132.

Torres Fontes, J. (1983). "El señorío de los Manuel en Montealgre”, in I Congreso de Historia de Albacete, vol. 2, pp. 81-92.

Zuazo y Palacios, J. (1916). Meca (Contribución al estudio de las ciudades ibéricas). Noticia de algunos descubrimientos arqueológicos en Montealegre (Albacete), Madrid. 